\title{
CARTAS DO MÉXICO. \\ UM OLHAR ANTROPOLÓGICO SOBRE \\ INTERCULTURALIDADE
}

\author{
LANDA $^{1}$, Mariano Báez \\ CIESAS/México
}

\section{RESUMO}

Este trabalho enfoca a relação entre a antropologia audiovisual e a comunicação intercultural, para desenvolver pesquisas sobre tecnologias digitais e comunicação intercultural, aplicando etnografias audiovisuais participativas para estimular a produção de jovens pertencentes a segmentos que não são visíveis na sociedade mexicana.

Palavras - chave: Antropologia audiovisual. Tecnologias digitais. Comunicación intercultural. Etnografias audiovisuais participativas.

\section{ABSTRACT}

This paper focuses on the relationship between audiovisual anthropology and intercultural communication, to develop research on digital technologies and intercultural communication, applying participatory audiovisual ethnographies to encourage the production of young people belonging to segments that are not visible in Mexican society.

Key words: Audiovisual anthropology. Digital Technologies. Intercultural comunication. Participatory audiovisual ethnographies.

\section{RESUMEN}

Este trabajo enfoca la relación entre antropologia audiovisual y comunicación intercultural, para desarrollar investigación aplicando etnografias audiovisuales participativas sobre el uso de tecnologias digitales y la producción de material multimédia entre jóvenes pertenecientes a segmentos poco visíbles de la sociedade mexicana.

Palabras clave: Antropologia audiovisual. Tecnologias digitales. Comunicación intercultural. Etnografias audiovisuales participativas.

1 CIESAS-México. 


\subsection{La práctica de la antropología por otros medios}

La antropología tiene en la etnografía su principal instrumento para el estudio de las culturas. La práctica etnográfica trabajó originalmente con imágenes producidas por los sentidos del investigador. Rápidamente nuestra disciplina incorporó tecnologías audiovisuales para escalar su capacidad de registro etnográfico como una verdadera extensión y expansión de sus sentidos. Así antropólogos, etnógrafos, viajeros, documentalistas comenzamos a utilizar el grabador de sonidos junto con las primeras cámaras de cine y fotografía ya desde finales del siglo XIX (Haddon 1898 Expedición Estrecho de Torres; Flaherty filma material etnográfico entre inuits de Canadá entre 1920-22 y Baldwin Spencer filma y fotografía aborígenes del norte australiano entre 1910-20; Mead y Bateson filman y graban en Bali durante la década de 1930).

La construcción y desarrollo de esta interfase tecnológica en la práctica de la antropología constituye la ampliación y fortalecimiento de su capacidad para representar la diversidad humana. El problema es que esa capacidad se ha desplegado, casi siempre, desde una posición que representa intereses, es decir, la utilización de filtros subjetivos y culturales que norman esa práctica de observación, descripción y explicación de los fenómenos de la vida humana.

Scott Robinson (1998) ha planteado que el oficio tradicional de la antropología visual ha sido ser cómplice de la expropiación de las imágenes de los otros utilizando un marco interpretativo de matriz colonial. Dicha expropiación se lleva a cabo mediante la violación de la intimidad cultural de los diferentes. Todo registro cultural de los otros es agresivo por su base hegemónica y los representadosinterpretados muchas veces no llegan a comprender su utilidad última, pese al carácter de denuncia que algunos materiales adoptan.

Las maneras de representar y construir la diversidad humana responden a racionalidades también diversas y muchas veces en tensión. Esto representa un imperativo ético-político que nos obliga a distinguir las estrategias de representación encaminadas a mantener las jerarquías y asimetrías en una sociedad, y aquellas que pretenden contribuir a la transformación del sistema de relaciones sociales basado en la reproducción de la desigualdad, la injusticia, la violencia y el poder. El trabajo científico, académico y artístico no escapa a las influencias de la teoría, la ideología, la posición política, los intereses y los valores del sujeto científico o artístico. 
Se precisa ensayar metodologías que permitan producir interconocimientos, es decir, lograr experiencias disciplinares y prácticas sociales colaborativas que logren trazar mapas de conocimientos interculturales e interepistémicos.

\subsection{Etnografía, medios audiovisuales y educación intercultural}

La integración nacional, para antropólogos como Moisés Sáenz (1939) debía ser planteada como una fusión de horizontes culturales que diera como resultado un nuevo proyecto de nación y una renovada civilización. Consideraba más necesario un programa de comunicación intercultural que un proyecto educativo, debido a la contradicción esencial que observaba entre el formato escolar hegemónico y universalizante, y la cultura de los pueblos originarios. No obstante, acreditaba en la necesidad de una estandarización lingüística basada en el castellano, que permitiese la comunicación franca entre las distintas culturas que integrarían al México nuevo.

Hoy en día, cerca de un millón de jóvenes mexicanos procedentes de hogares de baja renta constituyen la demanda potencial de educación superior en México. De ellos sólo el 20 por ciento logran realizar estudios universitarios.

La población indígena de México representa poco más del $10 \%$ de la población nacional. Sin embargo, se estima que apenas un $1 \%$ de la matrícula de educación superior es indígena.

- $\quad 75 \%$ de los niños y jóvenes de 15 a 19 años no asiste a la escuela (educación media y superior).

- La cobertura de educación superior en su caso es 5 veces inferior al promedio nacional.

- Menos de 2\% de los jóvenes indígenas asiste a universidades interculturales e institutos tecnológicos.

- La asistencia a las instituciones de educación superior es hasta 60 veces inferior a la de los jóvenes con mayores ingresos.

- La inversión promedio por alumno en las universidades interculturales es de 1,200 dólares anuales, mientras que en promedio en las universidades públicas estatales es de 5,200 dólares ${ }^{2}$, lo que demuestra una política diferenciada de carácter discriminatorio.

2 México ocupa el penúltimo lugar de la OCDE en inversión pública por alumno (UNESCO; World Bank). 
- El estado mexicano destinó 5\% del gasto federal a la educación pública en 2015.

Las universidades interculturales mexicanas son proyectos educativos que surgieron impulsados por la Secretaría de Educación Pública a partir del año 2000 durante el sexenio de Vicente Fox, por cierto el primer presidente mexicano que rompió la hegemonía del PRI, la máquina institucional que consolidara el presidente Cárdenas 60 años atrás. Debe anotarse aquí la excepción de la Universidad Autónoma Indígena de México (UAIM) en Sinaloa, que fue creada originalmente como un proyecto de docencia e investigación etnológica en 1982. Las demás universidades interculturales dependen primordialmente del financiamiento estatal y federal, así como de las decisiones que tomen sobre ellas los gobernantes. $\mathrm{Su}$ propósito institucional es explorar modalidades de atención educativa pertinente para jóvenes que aspiren a cursar el nivel de educación superior, tanto de origen indígena como de otros sectores sociales, interesados en impulsar fundamentalmente el desarrollo de los pueblos y comunidades indígenas y en aplicar los conocimientos construidos en contextos culturalmente diversos. Algunas personas afirman que fue una conquista del movimiento zapatista de 1994, otras las identifican como una estrategia del gobierno Fox para cooptar demandas del movimiento indígena.

Las universidades interculturales mexicanas se encuentran establecidas en 11 Estados del país Sinaloa, Michoacán, San Luis Potosí, Estado de México, Hidalgo, Puebla, Veracruz, Guerrero, Chiapas, Tabasco y Quintana Roo, la mayoría en regiones, municipios y zonas marginales con los menores índices de desarrollo humano (IDH), donde la desigualdad es una constante entre estos grupos de población y se manifiesta en graves problemas sociales entre los que se destacan: el acceso a los servicios de salud, presentación de enfermedades relacionadas con la pobreza, escasas fuentes de empleos, alimentación deficiente, baja cobertura en educación; es importante resaltar que derivado de su ubicación podemos señalar que las universidades tienen en su área de influencia municipios en donde el tema de la seguridad nacional es vital, toda vez que el narcotráfico se ha convertido en un problema mayor.

Los programas de educación intercultural hasta ahora, insertos en el modelo educativo nacional, no son mas que una perversión pedagógica porque plantea un diálogo de saberes horizontal y simétrico entre culturas, pasando por alto la determinación de un 
sistema social cuyas relaciones son asimétricas y se encuentran enmarcadas por estructuras de poder y dominación. Las universidades interculturales encierran en si mismas un contrasentido ya que el espíritu universalista de las instituciones de educación superior, como proyecto universitario occidental, formatea y reproduce una educación monocultural y monoepistémica entre sus miembros, es decir, universaliza una sola cultura llamada 'ciencia'. En otros casos se habla de interculturalidad como un nuevo paradigma educativo, como una nueva pedagogía que promueve la discriminación positiva de los indios, su autoreconocimiento y afirmación étnico cultural para apropiarse de los conocimientos occidentales e incorporarlos a un universo epistémico inmutable, conservador y en constante resistencia. Esta postura tiene una buena dosis de relativismo, donde el propio concepto de cultura se confunde con una identidad étnica sempiterna.

El término interculturalidad ha virado moda en los últimos años, como un adjetivo que califica mágicamente cualquier planteamiento y acción que dice reconocer y atender la diversidad cultural, utilizando un discurso políticamente correcto de defensa a ultranza de las tradiciones, costumbres y conocimientos ancestrales de los llamados pueblos originarios (muchas veces lesionando los derechos de terceras personas) como un imperativo ético-político frente a las amenazas del capitalismo neoliberal.

Así, se habla incluso de la interculturalidad como un nuevo estadio de desarrollo humano, como proyecto cultural alternativo que presupone un plano horizontal de comunicación, intercambio y cooperación del conocimiento. Evidentemente esta interculturalidad idílica no corresponde a la experiencia del mundo vivo, el cual se encuentra atravesado por las categorías de etnia, raza, clase, género y sexualidad, y donde se condensan las relaciones sociales basadas en la fricción, el conflicto, la negación del otro, el racismo, la desigualdad económica, la homofobia, el sexismo, la violencia y el miedo a la diferencia.

La interculturalidad a mi entender, constituye un espacio interfásico que relaciona a varias culturas y éste está atravesado por las múltiples determinaciones de la vida social que no se circunscribe a los llamados pueblos originarios.

$\mathrm{La}$ interculturalidad realmente existente, se compone de aproximaciones emprendidas desde varias ópticas culturalmente diferenciadas, para construir puentes entre poblaciones e individuos de culturas distintas. Parte de un concepto dinámico y diacrónico 
de la cultura que se desarrolla en escenarios de relaciones sociales asimétricas y enmarcadas por estructuras de poder. Es ante todo una interfase comunicativa que aspira a crear competencias suficientes que hagan posible un verdadero diálogo entre culturas. Por ello el llamado diálogo de saberes solo puede establecerse entre las culturas realmente existentes, que producen nuevos componentes y que se apropian de otros, que se transforman y adaptan permanentemente para no desaparecer o ser asimiladas.

\subsection{Tecnologias digitales y comunicación intercultural}

En un mundo global, asimétrico, desigual, injusto y culturalmente diverso, las acciones con un enfoque intercultural de mayor impacto no se dan en el ámbito de la educación, sino en el terreno de la comunicación y los multimedios que cada día se perfila mas como arena de la lucha social y política. En los últimos años destaca por ejemplo el movimiento \#Yo soy 132 que surge en 2012 sin una vanguardia explícita, aparece como una primera erupción visible (Galindo y González 2013) de un movimiento social juvenil con características inéditas que pone en jaque, por varios meses, a los monopolios de la comunicación en México utilizando comunicación digitaly las llamadas redes sociales para reclamar una democratización de los medios y una apertura a la voz e imágenes de los sectores segregados por la política y la estética de grupos dominantes que se auto reconocen como la gente bonita (Grupo Televisa). Más recientemente los desgarradores hechos de Ayotzinapa, donde desaparecieron y presumiblemente fueron brutalmente asesinados 45 estudiantes, que soñaban con ser profesores rurales, a manos de fuerzas combinadas del poder público y el crimen organizado, han desplegado un movimiento global solidario que involucra toda clase de actores sociales y políticos de nivel internacional, entre ellos el Papa, el presidente del Banco Mundial y muchos artistas y deportistas que han utilizado plataformas convencionales y alternativas de comunicación, para expresar solidaridad con las familias de esos jóvenes, lo novedoso del asunto es que ese movimiento juvenil, sin vanguardia visible, convierte los megashows y los partidos de fútbol en verdaderas megaprotestas demandando justicia y la renuncia de los gobernantes ineptos y corruptos que expresan cínicamente en los medios de comunicación masiva que ya se cansaron. 
En Argentina, las administraciones Kirschner lograron promulgar leyes que combaten a los monopolios privados de los medios de comunicación y favorecen el surgimiento de medios locales y regionales que detonen procesos comunicativos alternativos al discurso hegemónico.

La multimedia y las llamadas redes sociales se han convertido en una arena de combate por las ideas, los principios y los intereses de grupos y sujetos determinados. También es el lugar donde se expresan acciones de denuncia y se produce y transmite información de variada índole a través de dispositivos móviles y plataformas de intercomunicación que escapan al control monopólico de los grandes medios. Sin duda también es el espacio donde concurren acciones que buscan el reconocimiento de grupos étnicamente diferenciados y que nos plantea la urgente necesidad de poner en movimiento procesos de comunicación intercultural que vayan mas allá de las luchas por el reconocimiento y establezcan mecanismos de respeto y convivencia duraderos entre las múltiples manifestaciones de la diversidad humana.

Hoy en día las tecnologías digitales se han convertido en una poderosa interfase comunicativa entre comunidades e individuos. El acceso y uso de estas tecnologías ha impactado fuertemente a la estructura de las relaciones y movimientos sociales, la cultura y las relaciones interétnicas e interculturales. Prácticamente la interacción social se desarrolla en dos ámbitos constitutivos de las nuevas relaciones sociales: ON LINE y OFF LINE, es decir, aquellas prácticas mediadas tecnológicamente que producen una realidad que conecta aparatos e individuos dentro de un medio que es generado por una aplicación informática ó software, y aquellas que ocurren fuera de este ámbito (Domínguez Figaredo 2012).

Las relaciones sociales $O N$ LINE se califican según su grado de digitalización y conectividad, es decir, conforme al nivel de acceso y utilización de los medios digitales y, conforme a la capacidad del individuo para actuar en diversos contextos de acción. Las tecnologías digitales expanden y potencian esa capacidad (op. cit).

El acceso a las nuevas tecnologías es cada día mayor y mas fácil para una buena parte de la población, especialmente la telefonía celular que permite acceder a sistemas de mensajería instantánea y las llamadas redes sociales, pero no ocurre lo mismo con su conectividad, que depende sustancialmente de poder ocupar espacios digitales que, hoy por hoy, interactúan intensamente con las dimensiones físicas de la realidad. 
Para contribuir realmente a una integración social, sin menoscabo de la diversidad cultural, es preciso generar estrategias de conectividad que expandan las capacidades de actuación de individuos y comunidades, hoy marginales, para conseguir reconocimiento y garantizar respeto y convivencia en el conjunto de la sociedad.

\subsection{Etnografías audiovisuales participativas}

El fundamento de las etnografías audiovisuales participativas lo encontramos en la propuesta de Investigación-Acción Participativa (IAP) de Orlando Fals Borda (1973 y 1999) y de FOTOVOZ (Wang y Burris, 1997) que impulsan procesos de reciprocidad simétrica entre investigadores e investigados para superar la arrogancia académica y entablar compromisos de solidaridad, cambio social y producción de interconocimientos que se expresen a través de nuevas y/o diferentes narrativas de corte intercultural.

A través de la confección de guiones y argumentos, resultantes de diálogos interétnicos e interculturales mediados por procesos de comunicación audiovisual, se integran grupos focales y foros temáticos de análisis de materiales audiovisuales que destaquen problemas y temas generadores, para después montar talleres de producción multimedia basados en el uso de teléfonos celulares, redes sociales y plataformas abiertas de intercambio y colaboración de información preferentemente de tipo audiovisual. Con ello se pretende elevar índices de conectividad de colectivos étnica y culturalmente diferenciados que han experimentado un considerable distanciamiento y marginación de las prácticas comunicativas de nuestra sociedad, a pesar de contar hoy con un creciente índice de digitalización a través del uso de la telefonía celular y las llamadas redes sociales.

Desde el año 2001 funciona en la sede Golfo del CIESAS el Taller Miradas Antropológicas (TMA). Una de sus principales líneas de trabajo es la producción de materiales audiovisuales que contribuyan a generar ejercicios de reconocimiento de la diversidad sociocultural, empleando para ello fotografía y video etnográfico y documental (CIESAS-TMA Xalapa 2003 y Mérida 2006-7). En estas primeras producciones se integraron varios equipos de trabajo compuestos en forma interdisciplinaria y se buscó la participación de poblaciones involucradas en los registros audiovisuales. Las 
experiencias recabadas al respecto engloban reacciones del público de la mas diversa índole, desde quienes consideran una manipulación mediática hasta aquellos que externan tristeza, pesar y lágrimas al verse identificados de alguna manera con los hechos en pantalla. El objetivo se consigue al generar esos planos de ejercicio del reconocimiento de la diversidad humana en sentido positivo como también a través de la negación a reconocerla.

Sin duda alguna es muy significativo el reconocimiento que en 2015 hizo la American Anthropological Association (AAA 2015) de la importancia de los medios audiovisuales en la práctica etnográfica, en la producción de conocimientos, en el desarrollo sociocultural, en el debate teórico, en la educación y en las acciones junto a comunidades de la mas diversa índole, refiriéndose a la ethnographic visual media como una herramienta de la mayor importancia para la producción y aplicación del conocimiento antropológico.

\section{REFERÊNCIAS BIBLIOGRÁFICAS}

American Anthropological Association (2015). Sitio Web: http://www. americananthro.org/ConnectWithAAA/Content.aspx? ItemNumber $=194$. Consulta 04-02-2017.

Dominguez Figaredo, D. (2012). "Escenarios hibridos, narrativas transmedia, etnografía expandida". Revista de Antropología Social, UNED Núm. 21: 197-215, España.

Fals-Borda, Orlando (1973). "Reflexiones sobre la aplicación del método de investigación-acción en Colombia", en Revista Mexicana de Sociología, UNAM, IIS, vol. 35, Núm. 1, México.

Fals-Borda, Orlando (1999) "Orígenes universales y retos actuales de la IAP” en: Análisis Político, núm. 38, septiembre-diciembre, IEPRI, Universidad Nacional de Colombia, (fecha de consulta: 31 de julio de 2010) http:// bibliotecavirtual.clacso.org.ar/libros/colombia/assets/own/analisis $\% 20$ politico\%2038.pdf.

Galindo Cáceres, Jesús y José Ignacio González-Acosta (2013) \#YO SOY 132. La primera erupción visible. Global Talent University Press.

Robinson, Scott (1998). "Dilemas de la antropología visual mexicana", CUICUILCO vol. 5 núm. 13 ENAH, México.

Sáenz Garza, Moisés (1939). MEXICO INTEGRO. Torres Aguirre Imps. Lima. 
Sáenz Garza, Moisés (1936). CARAPAN. Bosquejo de una experiencia. Gil S. A. Lima.

Taller Miradas Antropológicas/CIESAS (2003) JÓVENES INDÍGENAS EN LA UNIVERSIDAD, Xalapa. https://vimeo.com/125176744. (2006-7) BA'AX KA WA'ALIK. Jóvenes mayas de Yucatán. Mérida. https://vimeo. com/125869880

Wang, Caroline y Mary Burris (1997), "Photo voice: concept, methodology, and use for participatory needs assessment", Health Education \& Behavior, University of Michigan vol. 24, núm. 3, junio, pp. 369-387, USA. 